\title{
Intestinal Parasite Infections among Inhabitants in Yanbian Prefecture, Jilin Province, China
}

\author{
Myoung-Ro Lee', Hee-Eun Shin', Byung-Suk Chung'1, Sang-Eun Lee', Jung-Won Ju', Liji Xu², Chen Long Nan², \\ Mi-Yeoun Park', Shin-Hyeong Cho,** \\ ${ }^{1}$ Division of Vectors and Parasitic Diseases, Centers for Disease Control and Prevention, Osong 28159, Korea; ${ }^{2}$ Yanbian Center for Disease Control \\ and Prevention, Yanbian Prefecture, China
}

\begin{abstract}
To investigate the prevalence of intestinal parasite infections in Yanbian Prefecture, Jilin Province, China, epidemiological surveys were conducted on a collaboration basis between the Korean Centers for Disease Control and Prevention and the Yanbian Center for Disease Control and Prevention. A total of 8,396 (males 3,737 and females 4,659) stool samples were collected from 8 localities and examined with the formalin-ether sedimentation technique, and additionally examined with the cellotape anal swab to detect Enterobius vermicularis eggs. The overall rate of intestinal parasites was $1.57 \%$. The prevalence of Ascaris lumbricoides was the highest ( $0.80 \%)$, followed by Entamoeba spp. (0.23\%), heterophyid flukes $(0.15 \%)$, Clonorchis sinensis $(0.08 \%)$, Enterobius vermicularis $(0.07 \%)$, hookworms $(0.06 \%)$, Trichostrongylus spp. (0.06\%), Giardia lamblia (0.04\%), Paragonimus spp. (0.02\%), Diphyllobothrium spp. (0.02\%), Trichuris trichiura $(0.02 \%)$. The prevalence by sex was similar, $1.58 \%(n=59)$ in males and $1.57 \%(n=73)$ in females. By the present study, it is partly revealed that the prevalences of intestinal parasite infections are relatively low among the inhabitants of Yanbian Prefecture, Jilin Province, China.
\end{abstract}

Key words: Prevalence, intestinal parasite, fecal examination, Yanbian, China

Intestinal parasitic infections remain a major public health problem worldwide. A significant proportion of these infections occur in the populations of Southeast Asia and the developing countries. In 2008, approximately 500 million people were estimated to harbor soil-transmitted nematode infections and over 40 million people were considered to have foodborne trematode infections [1].

There were a few national survey reports on intestinal helminth infections in China, including soil transmitted nematodes and food-borne trematodes. The number of individuals infected with soil-transmitted helminths in China is estimated to be 129 million, with more than 12 million infected with $C$. sinensis [2-5]. The previous report showed that the prevalence of soil-transmitted intestinal nematodes, such as Ascaris lumbricoides, Trichuris trichiura, and hookworms, was $4.6 \%$ in Jilin Province in 2003 [6]. The prevalence of Clonorchis sinensis infection was reported as high as $18.5 \%$ in Jilin Province from

\footnotetext{
- Received 9 December 2016, revised 4 July 2017, accepted 18 August 2017.

*Corresponding author (malpara2016@gmail.com)

(c) 2017, Korean Society for Parasitology and Tropical Medicine

This is an Open Access article distributed under the terms of the Creative Commons Attribution Non-Commercial License (http://creativecommons.org/licenses/by-nc/4.0) which permits unrestricted non-commercial use, distribution, and reproduction in any medium, provided the original work is properly cited.
}

2004 to 2012 [7].

Jilin Province is partly bordered by the northeast Russia and North Korea, and larger than the Republic of Korea. Yanbian Prefecture is located at South-Eastern part of Jilin Province, and designated as an autonomous region due to the vast inhabitation of ethnic Korean populations. On the other hand, there were only a few epidemiological studies on the prevalence of intestinal parasites in Jilin Province. Moreover, there is no report on the intestinal parasitic infections in Yanbian Prefecture. Therefore, we investigated the prevalence of parasitic infections among inhabitants in Yanbian Prefecture by a collaborative project between Korea and Yanbian.

This study was conducted in Yanbian Prefecture between July 2006 and September 2013. Yanbian Prefecture is administratively divided into 6 cities and 2 counties: Longing City, Yanji City, Dunhua City, Hunchun City, Helong City, Tumen City, Wangqing County, and Antu County (Fig. 1). Fecal specimens were collected from 8,396 inhabitants selected from the 8 regions ( 6 cities and 2 counties). These specimens were transferred to the laboratories of the Yanbian Center for Disease Control and Prevention for analyses. The formalin-ether sedimentation technique was used to determine the presence of helminth eggs and protozoan cysts, and for 8,396 inhabit- 


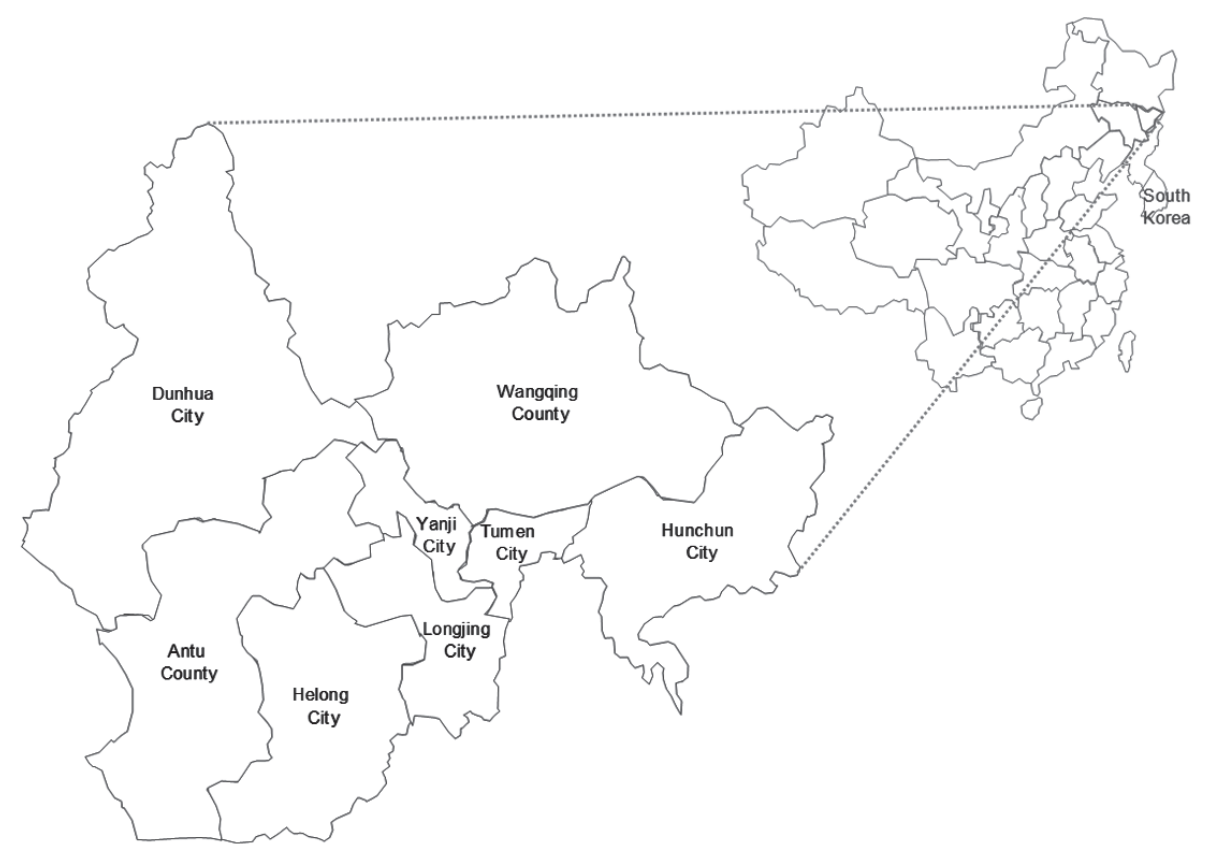

Fig. 1. Surveyed areas, 6 Cities and 2 Counties, in Yanbian Prefecture.

ants, cellotape anal swap was used to detect the presence of Enterobius vermicularis $[8,9]$. Parasite-positive individuals were treated with appropriate anti-parasitic drugs at the end of the survey. Fisher's exact test or chi-square test for trends were performed for categorical variables. SPSS 12.0 (SPSS, Chicago, Illinois, USA) was used for all statistical analyses. Statistical significance was set at a $P$-value of less than 0.05 .

Among 8,396 inhabitants participated in the survey, 132 $(1.57 \%)$ were infected with various intestinal parasites. Ascaris lumbricoides was the most common, with an average egg-positive rate of $0.80 \%$. The rate for $A$. lumbricoides was the highest in Longiing City (Table 1). The other prevalent species in Yanbian Prefecture was Entamoeba spp. (0.23\%), followed by heterophyid flukes $(0.15 \%)$, C. sinensis $(0.08 \%)$, Enterobius vermicularis (0.07\%), hookworms (0.06\%), Trichostrongylus spp. (0.06\%), Giardia lamblia (0.04\%), Paragonimus spp. (0.02\%), Diphyllobothrium spp. (0.02\%), and Trichuris trichiura (0.02\%). A total of 8,396 fecal samples were collected to survey; 2,162 from Wangqing County, 2,012 from Longing City, 1,714 from Yanji City, 508 from Tumen City, and 500 each from Dunhua City, Hunchun City, Helong City, and Antu County. The infection rate of parasites was highest in Longjing (2.04\%), followed by Tumen (1.77\%), Yanji (1.69\%), Antu (1.60\%), Dunhua $(2.20 \%)$, Helong $(1.40 \%)$, Wangqing $(1.02 \%)$, and Hunchun $(1.0 \%)$ (Table 1$)$. Overall prevalence for intestinal para- sites were $1.58 \%(0-2.16 \%)$ in males and $1.57 \%(0.58-3.73 \%)$ in females, respectively (Table 2).

By the present study, it has been confirmed for the first time that the prevalence of intestinal parasites is relatively low in the residents of Yanbian Prefecture, Jilin Province, China. They are also very low when we compared with those of the previous study performed in the other regions of Jilin Province. In case of A. lumbricoides infection, the prevalence was $0.80 \%$ in our study, but it was $4.6 \%$ in a previous study [6]. The prevalence of soil-transmitted helminths, i.e., A. lumbricoides, T. trichiura, and hookworms, are variable according to surveyed areas, and they are closely related with environmental conditions, rural or urban, and agricultural or industrial regions. The low proportion of farming population in Yanbian Prefecture could explain, at least partly, the low prevalence of A. lumbricoides infection [10].

The prevalence of $C$. sinensis infection in Yanbian Prefecture in this study was much lower than that in Jilin Province, in a survey performed from 2004 to 2014 [11]. The ecological factors, i.e., intermediate hosts for larval worm development and definitive hosts for egg supply, are essential to maintain the life cycle of this liver fluke. Additionally, traditional habit of eating raw fish by residents is an important factor to maintain the endemicity of clonorchiasis epidemiologically. Fortunately, there are few ecological and epidemiological factors favorable for $C$. 


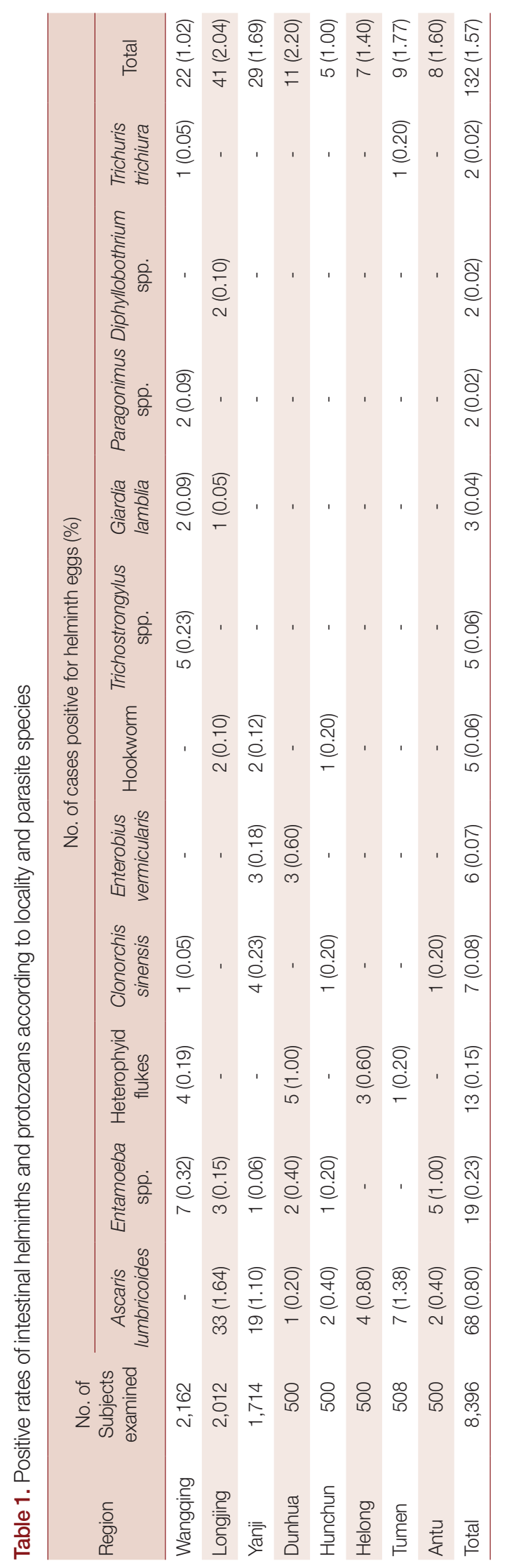

Table 2. Positive rates of intestinal parasites according to locality and gender

\begin{tabular}{lrrr}
\hline \multirow{2}{*}{ Localities } & \multicolumn{3}{c}{ No. positive / No. examined (\%) } \\
\cline { 2 - 4 } & \multicolumn{1}{c}{ Male } & \multicolumn{1}{c}{ Female } & \multicolumn{1}{c}{ Total } \\
\hline Wangqing County & $16 / 1,135(1.41)$ & $6 / 1,027(0.58)$ & $22 / 2,162(1.02)$ \\
Longjing City & $16 / 818(1.96)$ & $25 / 1,194(2.09)$ & $41 / 2,012(2.04)$ \\
Yanji City & $15 / 737(2.04)$ & $14 / 977(1.43)$ & $29 / 1,714(1.69)$ \\
Dunhua City & $0 / 205(0.00)$ & $11 / 295(3.73)$ & $11 / 500(2.20)$ \\
Hunchun City & $1 / 216(0.93)$ & $4 / 284(1.41)$ & $5 / 500(1.00)$ \\
Helong City & $3 / 223(1.35)$ & $4 / 277(1.44)$ & $7 / 500(1.40)$ \\
Tumen City & $3 / 172(1.74)$ & $6 / 336(1.79)$ & $9 / 508(1.77)$ \\
Antu County & $5 / 231(2.16)$ & $3 / 269(1.12)$ & $8 / 500(1.60)$ \\
Total & $59 / 3,737(1.58)$ & $73 / 4,659(1.57)$ & $132 / 8,396(1.57)$ \\
\hline
\end{tabular}

sinensis infection in Yanbian Prefecture. The water systems of river and lakes are not so developed, and then edible fish resources are not enough in this region.

In summary, our data showed various intestinal parasitic infections in the surveyed areas of Yanbian Prefecture, China; however, the prevalence rates were generally low. Although not conceptually new, our results are important because they provide basic data and important information about parasite infections in the Yanbian area.

\section{ACKNOWLEDGMENT}

This work was supported by the Endemic Diseases Control Program (NIH 4800-4847-311) from the National Research Institute of Health, Centers for Disease Control and Prevention, Ministry of Health and Welfare, Republic of Korea.

\section{CONFLICT OF INTEREST}

All authors declare no conflict of interest.

\section{REFERENCES}

1. Hotez PJ, Brindley PJ, Bethony JM, King CH, Pearce EJ, Jacobson J. Helminth infections: the great neglected tropical diseases. J Clin Invest 2008; 118: 1311-1321.

2. Qian MB, Xia S, Zhou XN. Soil-transmitted helminths in China. Lancet Infect Dis 2015; 15: 1262-1263.

3. Lun ZR, Gasser RB, Lai DH, Li AX, Zhu XQ, Yu XB, Fang YY. Clonorchiasis: a key foodborne zoonosis in China. Lancet Infect Dis 2005; 5: 31-41.

4. Liu C, Luo R, Yi H, Zhang L, Li S, Bai Y, Medina A, Rozelle S, Smith S, Wang G, Wang J. Soil-transmitted helminths in south- 
western china: a cross-sectional study of links to cognitive ability, nutrition, and school performance among children. PLoS Negl Trop Dis 2015; 9: e0003877.

5. Li T, He S, Zhao H, Zhao G, Zhu XQ. Major trends in human parasitic diseases in China. Trends Parasitol 2010; 26: 264-270.

6. Chen $\mathrm{YD}$, Zhou CH, Xu LQ. Analysis of the results of two nationwide surveys on Clonorchis sinensis infection in China. Biomed Environ Sci 2012; 25: 163-166.

7. Lai D-H, Hong XK, Su BX, Liang C, Hide G, Zhang X, Yu X, Lun ZR. Current status of Clonorchis sinensis and clonorchiasis in China. Trans R Soc Trop Med Hyg 2016; 110: 21-27.

8. Kim TS, Cho SH, Huh S, Kong Y, Sohn WM, Hwang SS, Chai JY, Lee SH, Park YK, Oh DK, Lee JK. Nationwide survey on the prev- alence of intestinal parasitic infections in the Republic of Korea, 2004. Korean J Parasitol 2009; 47: 37-47.

9. Cho SH, Lee KY, Lee BC, Cho PY, Cheun HI, Hong ST, Sohn WM, Kim TS. Prevalence of clonorchiasis in southern endemic areas of Korea in 2006. Korean J Parasitol 2008; 46: 133-137.

10. Meishan P, Chengnan Y, FUJIMOTO N. Industrial agglomeration in border areas in northeast China: the case of yanbian in the China-North Korea-Russia triangle border area. Innov Supply Chain Manag 2015; 9: 1-9.

11. Xue-Ming L, Ying-Dan C, Yi O, Hong-Man Z, Rui L, Wei M. Overview of human clonorchiasis sinensis in China. Southeast Asian J Trop Med Public Health 2011; 42: 248-254. 